\title{
Selective Nanotrench Filling by One-Pot Electroclick Self-Constructed Nanoparticle Films
}

\author{
Gaulthier Rydzek, Delphine Toulemon, Antonio Garofalo, Cedric Leuvrey, \\ Jean-François Dayen, Delphine Felder-Flesch, Pierre Schaaf, Loïc Jierry, \\ Sylvie Begin-Colin, Benoît P. Pichon, * and Fouzia Boulmedais*
}

Using nanoparticles (NPs) as building blocks is driving the emergence of a new class of nanoarchitectonics materials ${ }^{[1]}$ opening promising perspectives in several fields including energy conversion, ${ }^{[2]}$ catalysis, ${ }^{[3]}$ optical, ${ }^{[4]}$ biosensing, ${ }^{[5]}$ and stimuli-responsive devices. ${ }^{[6]}$ For instance, ferrimagnetic NPs will lead to next generation of high density magnetic storage

\author{
Dr. G. Rydzek, ${ }^{[+]}$Prof. P. Schaaf \\ INSERM, UMR-S 1121 \\ "Biomatériaux et Bioingénierie," \\ 11 rue Humann, F-67085 Strasbourg, Cedex, France \\ Dr. G. Rydzek, Prof. P. Schaaf \\ Faculté de Chirurgie Dentaire \\ Université de Strasbourg \\ 8 rue Saint Elisabeth, 67000 Strasbourg, France
}

Dr. D. Toulemon, Dr. A. Garofalo, Dr. C. Leuvrey, Dr. J.-F. Dayen,

Dr. D. Felder-Flesch, Prof. S. Begin-Colin, Dr. B. P. Pichon

Institut de Physique et Chimie des Matériaux de Strasbourg

Centre National de la Recherche Scientifique

Université de Strasbourg

UMR 7504

23 Rue du Loess BP 43, Strasbourg, Cedex 267034, France

E-mail: benoit.pichon@unistra.fr

Prof. P. Schaaf, Dr. L. Jierry, Dr. F. Boulmedais

Institut Charles Sadron

Centre National de la Recherche Scientifique

Université de Strasbourg

23 rue du Loess, BP 84047, 67034, Strasbourg, Cedex 2, France

E-mail: fouzia.boulmedais@ics-cnrs.unistra.fr

Prof. P. Schaaf

Institut Universitaire de France

103 boulevard Saint-Michel, 75005 Paris, France

Prof. P. Schaaf

International Center for Frontier Research in Chemistry

8 allée Gaspard Monge, 67083 Strasbourg, France

Prof. P. Schaaf, Dr. L. Jierry, Prof. S. Begin-Colin, Dr. B. P. Pichon

Université de Strasbourg

Ecole Européenne de Chimie

Polymères et Matériaux

25 rue Becquerel, 67087 Strasbourg, France

Dr. L. Jierry, Dr. F. Boulmedais

University of Strasbourg Institute for Advanced Study

5 allée du Général Rouvillois, 67083 Strasbourg, France

${ }^{[+]}$Present address: International Center for Young Scientists (ICYS), National Institute for Materials Science (NIMS), International Center for Materials Science (MANA), 1-1 Namiki, Tsukuba 305-0044, Japan

DOI: $10.1002 /$ smll.201500639 media $^{[7]}$ and magnetite NP films will find applications in spintronics. ${ }^{[8]}$ Surface functionalization by layer-by-layer, ${ }^{[9]}$ self-assembled monolayers, ${ }^{[10]}$ Langmuir-Blodgett, ${ }^{[11]}$ or dipcoating deposition ${ }^{[12]}$ were used to assemble NP platforms whose stability was recently improved by covalent reticulation. ${ }^{[13]}$ However, these techniques are still difficult to implement in electronic or photonic nanodevices, due to structural defects $^{[14]}$ and high sensitivity to chemical and electromagnetic environment. ${ }^{[15]}$ Dielectrophoresis is widely used to fill nanogaps and nanotrenches by NPs. However, it requires relatively large bias voltage $(>1 \mathrm{~V})$ and high frequencies (in order of $\mathrm{MHz}$ ), and is mostly applicable to easily polarizable suspended materials. ${ }^{[16]}$ Therefore, nanogap/nanotrench filling requires a simple and versatile strategy to generate robust and spatially confined NP-films. Such an achievement would support the tremendous emergence of nanogaps/ nanotrenches as circuit elements and biosensors. ${ }^{[17]} \mathrm{We}$ recently introduced a promising strategy for robust one-pot self-construction of polymeric films reticulated by a spatially confined $\mathrm{Cu}(\mathrm{I})$-catalyzed electroclick reaction. ${ }^{[18]}$ Alkyne and azide bearing organic building blocks were covalently assembled on surfaces by local electrochemical generation of $\mathrm{Cu}(\mathrm{I})$ from $\mathrm{Cu}(\mathrm{II})$ in solution. ${ }^{[19]}$ In this article, we report on the first covalent self-construction of NP films for selectively filling high aspect ratio nanodevices, composed of two gold electrodes separated by a $40 \mu \mathrm{m}$-long and $100 \mathrm{~nm}$-wide nanotrench. Dendronized iron oxide NPs bearing azide and alkyne functions were used as building blocks to achieve a spatially confined electroclick reticulation (Figure 1a) where (i) only one solution is used containing all the components, which do not react together, (ii) unless an external stimulus, i.e., cyclic voltammetry at low potentials and low scanning rate, launches the reaction locally, i.e., at the interface of the solution and the substrate.

Two different types of well-defined spherical shape iron oxide NPs coated with "clickable dendrons" have been synthesized by thermal decomposition with narrow size distribution centered at $9.0 \pm 0.8 \mathrm{~nm}(\mathrm{NP} 9)$ and $19.8 \pm 1.2 \mathrm{~nm}$ (NP20). ${ }^{20]}$ Size distribution of NP9 and NP20 diluted suspensions, obtained by transmission electron microscopy (TEM) and granulometry, are presented in Figure S1 in the Supporting Information. The as obtained nanoparticles have been further functionalized by two hydrophilic dendritic molecules (dendrons) bearing functional (azido, alkyne) poly(ethylene glycol) (PEG) chains at their periphery as well 


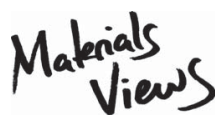

www.MaterialsViews.com
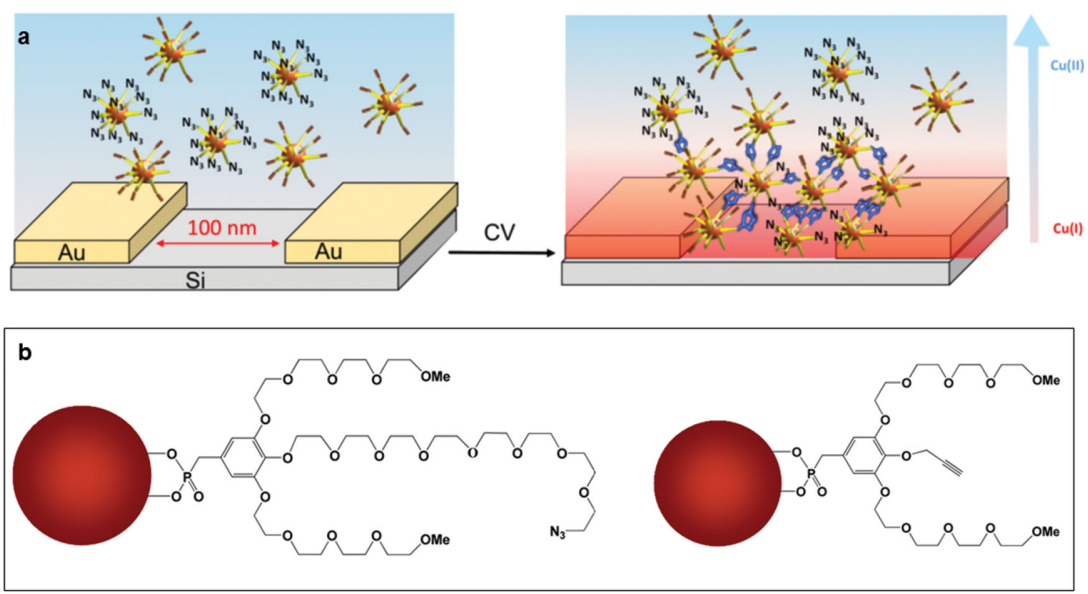

Figure 1. One-pot electroclick self-construction of NP films for selective filling of nanotrenches. a) Schematic representation of the electroclick self-construction process using building blocks composed of b) alkyne and azide functionalized iron oxide NPs that can react together in the presence of a $\mathrm{Cu}(\mathrm{I})$ gradient electrochemically generated from $\mathrm{Cu}(\mathrm{II})$ by application of a cyclic voltammetry (CV) at working electrodes.

as a phosphonic acid anchor at their focal point. Indeed to enhance stability of iron oxide NPs, we recently developed small-sized dendrons displaying at their focal point phosphonic acid groups, which are very strong anchors for the surface of iron oxide NPs and strongly limit their desorption on time. The coating of the NPs also confers good colloidal stability in water by steric repulsion due to PEG chains, thus reducing agglomeration effects, while preserving the

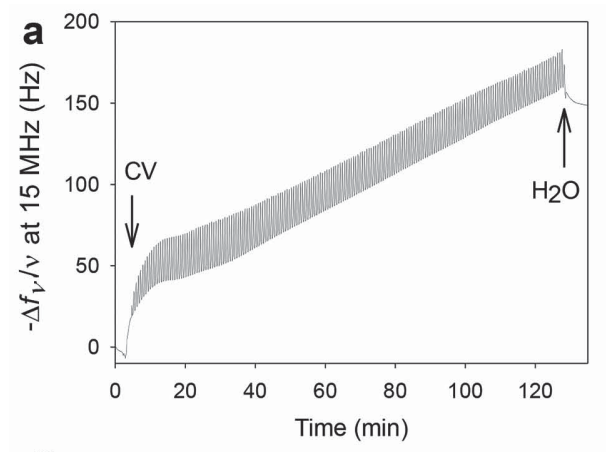

C
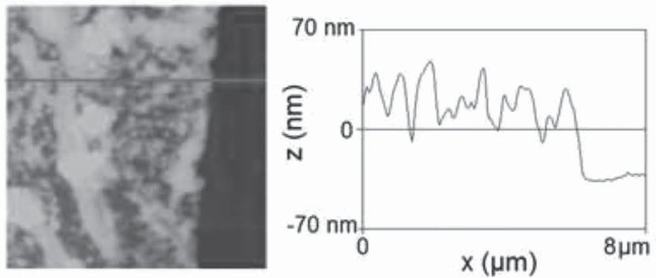

magnetic properties of the NPs. ${ }^{[20]} \mathrm{High}$ colloidal stability of functionalized $9 \mathrm{~nm}$ sized NPs (NP9-C $\equiv \mathrm{CH}$ and $\mathrm{NP} 9-\mathrm{N}_{3}$ ) and $20 \mathrm{~nm}$ sized NPs (NP20-C $\equiv \mathrm{CH}$ and NP20$\mathrm{N}_{3}$ ) was achieved in water and water/ dimethylformamide (DMF) (1:1 v/v) mixture, respectively. ${ }^{[20 a, 21]}$

Self-construction of NP films, from a mixture of NP9- $\mathrm{N}_{3}$ and $\mathrm{NP} 9-\mathrm{C} \equiv \mathrm{CH}$ in the presence of $\mathrm{CuSO}_{4}$, was studied by electrochemical quartz crystal microbalance (EC-QCM). An anchoring azide modified poly(ethylene imine) $\left(\mathrm{PEI}-\mathrm{N}_{3}\right)$ layer was first adsorbed on the working electrode to allow the deposition of NPs. This anchoring layer was deposited to favor the homogeneous deposition of NP on the QCM crystal by introducing clickable moieties on the crystal. Indeed, PEI is a branched polycation that adsorbed strongly on surfaces due to electrostatic interactions. After stabilization of the EC-QCM signal in the presence of NP mixture, application of a cyclic voltammetry (CV) between -350 and $+600 \mathrm{mV}$ (vs $\mathrm{Ag} / \mathrm{AgCl}$, scan rate of $50 \mathrm{mV} \mathrm{s}^{-1}$ ) induced a continuous increase of the normalized frequency shift, related to the deposited mass of a NP9 film (Figure 2a). Small oscillations are superimposed on the signal, resulting from cyclic electrochemical reversible formation and dissolution of a $\mathrm{Cu}(0)$ layer ${ }^{[18]}$ After $120 \mathrm{~min}$
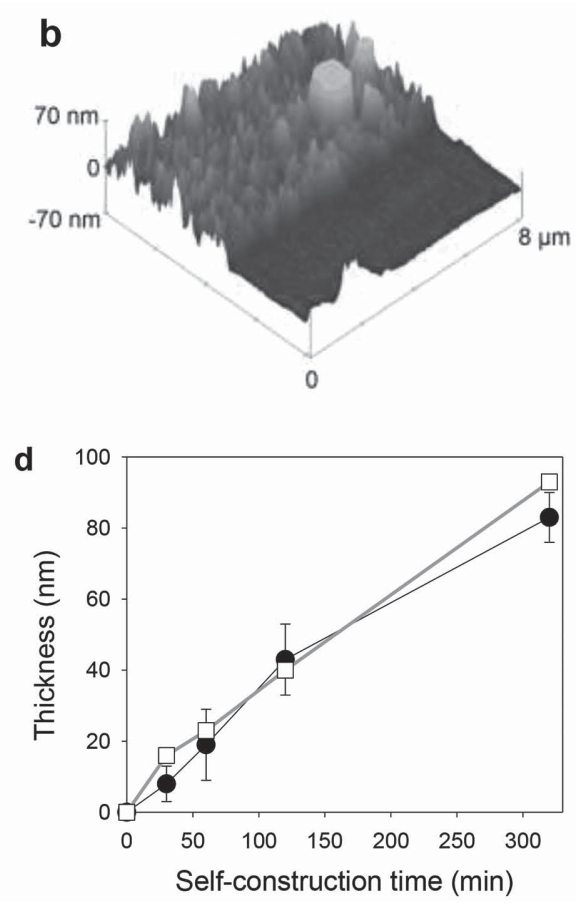

Figure 2. Characterization of electroclick self-constructed NP9 films. a) Evolution of the normalized frequency shift, measured by EC-QCM, during the self-construction of NP9 film. b) Typical 3D and c) 2D AFM height images $\left(8 \times 8 \mu \mathrm{m}^{2}, z\right.$-scale $\left.200 \mathrm{~nm}\right)$ with its corresponding cross-section profile (localized by the red line), obtained in contact-mode and in dry state, of a scratched self-constructed NP9 film. On the 3D AFM image, NP9 film is located on the background and the scratched zone on the foreground of the image. On the 2D AFM image, NP9 film is located on the left and the scratched zone on the right of the image. The film was obtained by application of CV during 120 min on a QCM gold crystal. d) Evolution of the film thickness, calculated with the Voigt-Voinova model ${ }^{[22]}$ (white square) and measured by AFM in dry state (black circle). 
of $\mathrm{CV}$, the normalized frequency shift reached $140 \mathrm{~Hz}$, corresponding to a $40 \mathrm{~nm}$ thick deposited film according to the Voigt-Voinova model. ${ }^{[22]}$ Normalized frequency shifts of the third, seventh, and ninth harmonics were superimposed suggesting the deposition of a rigid film, ${ }^{[23]}$ as expected for an NP-based film (Figure S-2 in the Supporting Information).

Atomic force microscopy (AFM) measurements give access to the film topography and thickness in the dry states (Figure 2b,c) and liquid (Figure S-3a-c in the Supporting Information). A fully covered substrate was obtained after $120 \mathrm{~min}$ of $\mathrm{CV}$ with a film roughness of $19 \mathrm{~nm}$, measured in dry state on $10 \times 10 \mu \mathrm{m}^{2}$ images. The film thickness, defined as the minimal thickness covering the whole substrate, was about $30 \mathrm{~nm}$ (corresponding to three times the diameter of NP9). Both topographies and thicknesses remained the same in the liquid and dry states which agree with the formation of a dense and poorly hydrated film of iron oxide NPs as confirmed by scanning electron microscopy (SEM) measurements (Figure S-3 in the Supporting Information). To be sure that the mass deposition was due to electroclick reticulation of NPs, control experiments were performed with only NP9$\mathrm{C} \equiv \mathrm{CH}$ or only NP9-N suspensions in the presence of $\mathrm{CuSO}_{4}$ (Figure $\mathrm{S}-4$ in the Supporting Information). In the case of $\mathrm{NP} 9-\mathrm{C} \equiv \mathrm{CH}$, no more than $47 \mathrm{~Hz}$ frequency shift was measured after $50 \mathrm{~min}$ of $\mathrm{CV}$ due to the electroclick reticulation of a NP9-C $\equiv \mathrm{CH}$ monolayer on the $\mathrm{PEI}-\mathrm{N}_{3}$ coated surface. By contrast, no mass deposition was observed when using NP9- $\mathrm{N}_{3}$. These results confirmed the ability of the one-pot electroclick self-construction approach to grow NP-based films as previously demonstrated with polymeric films. ${ }^{[18]}$ Electroclick chemistry is known to provide a fine thickness tuning in the case of polymer films by simply increasing the self-construction time. ${ }^{[18]}$ Thus, self-construction of NP9 films was monitored for $\mathrm{CV}$ application times from 30 to 320 min (Figure 2d and Figure S-5 in the Supporting Information). After $30 \mathrm{~min}$, the substrate was homogeneously covered by a $12 \mathrm{~nm}$ thick film, corresponding roughly to a NP9 monolayer. A nearly linear growth of the film thickness was measured, reaching $90 \mathrm{~nm}$ after $320 \mathrm{~min}$, which corresponds to ten times the diameter of NP9. The film expanded at a rate of $0.28 \mathrm{~nm} \mathrm{~min}{ }^{-1}$ corresponding to a new NP layer deposition every 36 min allowing thus a fine control of the thickness. There is a difference in the thickness measured by AFM and the one calculated from QCM data. As QCM is sensitive to the mass adsorbed on the crystal including the bound water, the surface roughness of NP9 film induces a larger hydrodynamic thickness measured by QCM compared to the thickness of the core determined by AFM. ${ }^{[24]}$ Trapped copper could be removed by washing NP9 films with $0.1 \mathrm{M}$ ethylenediaminetetraacetic acid (EDTA) (Figure S-6 in the Supporting Information).

Next generation of NP deposition methods needs to be versatile with respect to NPs and substrates types, shapes, and morphologies. The one-pot electroclick self-construction process is a promising candidate since the localized generation of $\mathrm{Cu}(\mathrm{I})$ catalyst adapts itself to the shape of the electrode. ${ }^{[25]}$ To demonstrate the versatility of this process, a gold wire of $0.5 \mathrm{~mm}$ diameter was used as working electrode to self-construct a NP9 film leading to similar coatings
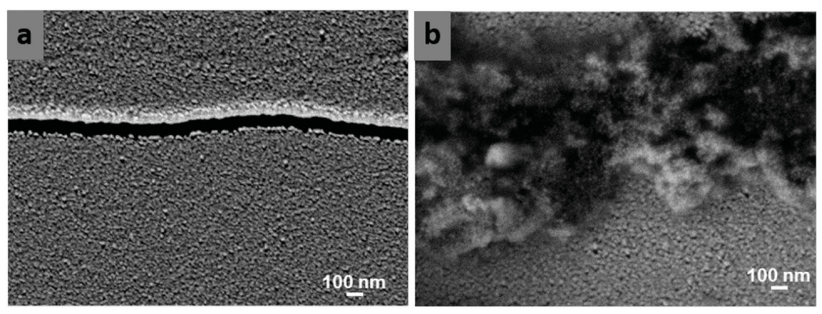

C

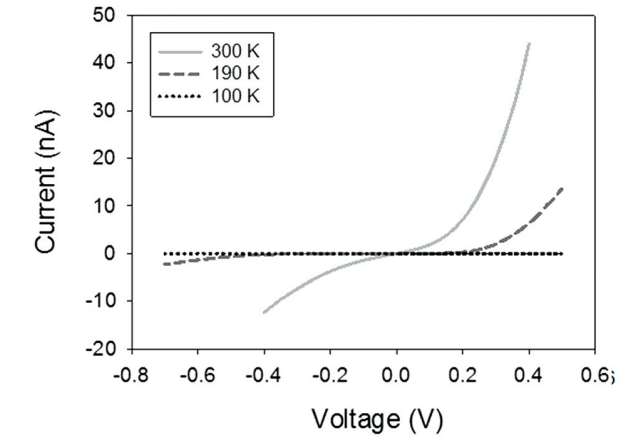

Figure 3. Nanotrench electrodes filling by self-constructed NP20 film. SEM micrographs of a $100 \mathrm{~nm}$-wide nanotrench a) before and b) after self-construction of a $\left(\mathrm{NP} 20-\mathrm{N}_{3}, \mathrm{NP} 20-\mathrm{C} \equiv \mathrm{CH}\right)$ film after $120 \mathrm{~min}$ of CV. c) Nonlinear intensity-potential curves, measured at different temperatures, on iron oxide $20 \mathrm{~nm}$ NP film specifically deposited in $100 \mathrm{~nm}$ wide nanotrenches.

as those deposited on QCM gold crystals (Figure S-7 in the Supporting Information). Without CV application, no film deposition was obtained on the wire, showing that NP film self-construction does not proceed spontaneously. Furthermore, the size of NPs was also increased to provide a conductive magnetite phase, ${ }^{[8]}$ leading to NP20 films on both gold wires (Figure S-7 in the Supporting Information) and gold wafers (Figure S-8 in the Supporting Information).

Finally, one-pot electroclick self-construction of NP20s was specifically addressed between nanotrenches. Iron oxide NP20 films were locally self-constructed between two gold electrodes, separated by a $40 \mu \mathrm{m}$-length and $100 \mathrm{~nm}$-wide nanotrench, to establish an electrical conductivity. Devices were composed of seven high aspect ratio nanotrenches and have been prepared by combining optical and shadow-edge lithography (Figure S-9 in the Supporting Information). ${ }^{\text {[26] }}$ All electrodes of the nanotrench device were connected together to act as a single working electrode in a three electrodes electrochemical setup (Figure S-10 in the Supporting Information). No PEI-N $\mathrm{N}_{3}$ layer was deposited to avoid any loss of conductivity. After $120 \mathrm{~min}$ of CV, SEM micrographs showed that NP20s have been mostly assembled between $100 \mathrm{~nm}$-wide nanotrench electrodes filling its whole length (Figure 3 and Figure S-11 in the Supporting Information). The selective filling of nanotrenches is likely explained by the enhancement of the electric field at the electrode edges favoring the reduction of $\mathrm{Cu}$ (II) into $\mathrm{Cu}(\mathrm{I})$ inside the nanotrench region (Figure $3 \mathrm{~b}$ ) and at the border of the electrodes (Figure S-12 in the Supporting Information). ${ }^{[27]}$

Bridging of nanotrench electrodes by self-constructed NP20 assemblies was confirmed by direct current electrical transport measurements (Figure 3c). Intensity-potential (I(V)) curves of filled nanotrenches exhibited clear signatures 
small

www.MaterialsViews.com

of electronic transport through the film. Indeed, the nonlinear behavior is related to intrinsic properties of iron oxide NPs, and more precisely to Coulomb blockade of electrons due to high charging energy of NPs. A similar signature was obtained for Langmuir-Blodgett deposited NP20 films. ${ }^{[8]}$ Electrical transport through magnetic NP networks can be described in terms of electronic transport through magnetic conducting islands separated by insulating barriers. Electrons have to tunnel between successive NPs across the trench. The high charging energy of NPs makes the co-tunneling regime relevant at room temperature. ${ }^{[28]}$ An asymmetric I(V) behavior is observed on the contrary to our previous work. ${ }^{[8]}$ This is a direct consequence of both the asymmetry in the nanotrench architecture (with one electrode being twice higher than the other ${ }^{[26]}$ and the much stronger interparticle coupling in the presently studied NP network promoting charge injection through the whole thickness of the injecting electrode. This strong interparticle coupling, being two orders of magnitude higher than in our previous work, arises from a larger conductive core of the NP and a much shorter organic spacer, around 17 and $1 \mathrm{~nm}$, respectively, in this work, compared to 13 and $2 \mathrm{~nm} .{ }^{[8]}$

In summary, 3D NP-based films were self-constructed by one-pot electroclick approach. This strategy is versatile with respect to the types of NPs and of substrates and leads to high quality covalent inorganic films with a fine thickness control. Overcoming an open challenge in nanoscience, it appears particularly suitable for filling selectively nanotrench electrodes with conductive iron oxide NP20 to establish an electrical conductivity. Furthermore, this approach being based on the functionalization of nanoparticles, it is expected to be strongly versatile and may be applied to other types of nanoparticles having clickable moieties. ${ }^{[29]}$ This assembling strategy thus represents a promising tool to integrate covalent NPs films into nanodevices, opening the route for biosensing and granular electronic devices.

\section{Experimental Section}

Synthesis of $9 \mathrm{~nm}$ Sized Iron Oxide Nanoparticles (NP9): NPs were synthesized by the thermal decomposition method ${ }^{[21 a]}$ based on our previous work. ${ }^{[20 a, 30]}$

Synthesis of $20 \mathrm{~nm}$ Sized Iron Oxide Nanoparticles (NP20): Iron stearate $\left(\mathrm{Fe}(\text { stearate })_{2}\right)\left(1.38 \mathrm{~g}, 2.2 \times 10^{-3} \mathrm{~mol}\right)$ was dissolved in docosene $(20 \mathrm{~mL})$ in the presence of oleic acid $(1.24 \mathrm{~g}$, $\left.3.3 \times 10^{-3} \mathrm{~mol}\right)$. The mixture was kept at $110^{\circ} \mathrm{C}$ for at least $4 \mathrm{~h}$ and then refluxed with a heating rate of $5{ }^{\circ} \mathrm{C} \mathrm{min}-1$ for $120 \mathrm{~min}$ under air without stirring. After cooling at RT, the black suspension was washed 12 times with a mixture of hexane and acetone (v:v, 1:4) and centrifuged (14 $000 \mathrm{rpm}, 10 \mathrm{~min}$ ). The $19.8 \mathrm{~nm}$ obtained nanoparticles were easily suspended in tetrahydrofuran (THF) at a concentration of $1.67 \mathrm{mg} \mathrm{mL}^{-1}$.

Synthesis of Dendritic Molecules: We previously reported on the synthesis of these two functional dendrons. ${ }^{[20 b, c]}$

Nanoparticle Functionalization: $11.7 \mathrm{mg}$ (resp., $23.4 \mathrm{mg}$ ) of dendritic molecules bearing azide (resp., alkyne) groups were solubilized in $16 \mathrm{~mL}$ of THF. The solution was added to a $4 \mathrm{~mL}$ of a suspension of oleic acid coated NP9 or NP20 (at 5 and
$1.67 \mathrm{mg} \mathrm{mL}^{-1}$, respectively) in THF and stirred for $15 \mathrm{~h}$. The excess of dendritic molecules and desorbed oleic acid were removed by ultrafiltration (using a $30 \mathrm{kDa}$ membrane, Millipore) in $60 \mathrm{~mL}$ of the corresponding solvent. The obtained NPs were redispersed in $20 \mathrm{~mL}$ of water in the case of NP9 and $20 \mathrm{~mL}$ of a DMF/water ( $\mathrm{v}: \mathrm{v}$, 1:1) mixture in the case of NP20.

Electrochemical Quartz Crystal Microbalance with Dissipation Monitoring (EC-QCM): Experiments were performed on a Q-Sense E1 apparatus from Q-Sense AB (Gothenburg, Sweden). Changes in the resonance frequency $f$ and in the dissipation factor $D$ of an oscillating quartz crystal were monitored. ${ }^{[31]}$ They are due to the mass of the film deposited as well as to the viscoelastic characteristics of the film. ${ }^{[22,31]}$ Simultaneous QCM and electrochemistry measurements are allowed by the Q-Sense Electrochemistry Module (QEM 401) and PGU MOD potentiostat (Jaissle Elektronik $\mathrm{GmbH}$, Germany) using a gold-coated QCM sensor from Q-Sense $A B$ (Gothenburg, Sweden) as working electrode.

Cyclic Voltammetry: Outside of the EC-QCM cell, a three electrodes electrochemical setup was used. The counter electrode was a platinum wire, the reference electrode was the same as in the EC-QCM, and the working electrode was either a gold wafer, a gold wire, or $100 \mathrm{~nm}$ nanotrenches electrodes.

TEM: A TOPCON model 002B TEM, operating at $200 \mathrm{kV}$ was used with a point-to-point resolution of $0.18 \mathrm{~nm}$. The polydispersity in size was calculated from size measurements of more than 300 nanoparticles.

Granulometry: A nanosize MALVERN (nano ZS) apparatus was used in water or dimethylformamide.

Fourier Transformed Infrared Spectroscopy (FTIR): It was performed with a Digilab Excalibur FTS 3000 series spectrometer.

AFM: Images were obtained by AFM in contact mode in liquid and dry states using Nanoscope IV from Veeco (Santa Barbara, CA) with silicon nitride cantilevers, spring constant $0.03 \mathrm{~N} \mathrm{~m}^{-1}$ (model MSCTAUHW, Veeco, CA).

Film Buildup Procedure: Films were assembled on cleaned substrates by first adsorbing during $5 \mathrm{~min}$ a PEI- $\mathrm{N}_{3}$ layer from a $1 \mathrm{mg} \mathrm{mL} \mathrm{m}^{-1}$ aqueous solution at $\mathrm{pH} 7$, except for nanotrenches device experiments. The self-construction was obtained by injection in the EC-QCM cell at $0.1 \mathrm{~mL} \mathrm{~min}^{-1}$ of $\left(0.5 \mathrm{mg} \mathrm{mL}^{-1}\right.$ NP- $\left.\mathrm{N}_{3}, 0.5 \mathrm{mg} \mathrm{mL}^{-1} \mathrm{NP}-\mathrm{C} \equiv \mathrm{CH}\right)$ mixture suspension containing $1.2 \times 10^{-3} \mathrm{M}$ copper(II) sulfate pentahydrate $\left(\mathrm{CuSO}_{4} \cdot 5 \mathrm{H}_{2} \mathrm{O}, 99.99 \%\right.$ purity, CAS 7758-99-8) at $\mathrm{pH} 6$. CV between -350 and $+600 \mathrm{mV}$ with a $50 \mathrm{mV} \mathrm{s}^{-1}$ scan rate was applied to induce self-constructions up to $320 \mathrm{~min}$. When the film was built outside of the EC-QCM cell, the building solution was stirred with a magnetic bar.

Nanotrench Fabrication and Electrical Measurements: Nanotrenches devices were prepared according to Dayen et al. ${ }^{[26]}$ Low-temperature DC electrical measurements were carried out inside a closed cycle helium cryostat, using a Keithley 2634B high precision multimeter.

\section{Supporting Information}

Supporting Information is available from the Wiley Online Library or from the author. 


\section{Acknowledgements}

G.R. and D.T. contributed equally to this work. This research was supported by a grant from ANR (project "Morphobuildup" ANR13-JS08-0003-01). G.R. thanks the French ministry of research for granting doctoral fellowship. D.T. thanks the Direction Générale de l'Armement (DGA) and Région Alsace for granting doctoral fellowship.

[1] a) M. Aono, Y. Bando, K. Ariga, Adv. Mater. 2012, 24, 150; b) K. Ariga, M. Li, G. J. Richards, J. P. Hill, J. Nanosci. Nanotechnol. 2011, 11, 1.

[2] A. C. Arango, L. R. Johnson, V. N. Bliznyuk, Z. Schlesinger, S. A. Carter, H. H. Horhold, Adv. Mater. 2000, 12, 1689.

[3] H. Wang, S. Ishihara, K. Ariga, Y. Yamauchi, J. Am. Chem. Soc. 2012, 134, 10819.

[4] M. Pelton, J. Aizpurua, G. Bryant, Laser Photon. Rev. 2008, 2, 136.

[5] M. Bally, J. Voros, Nanomedicine 2009, 4, 447.

[6] K. Ariga, Q. Ji, J. P. Hill, Y. Bando, M. Aono, NPG Asia Mater. 2012, 4, e17.

[7] S. A. Majetich, Y. Jin, Science 1999, 284, 470.

[8] M. Pauly, J. F. Dayen, D. Golubev, J. B. Beaufrand, B. P. Pichon, B. Doudin, S. Begin-Colin, Small 2012, 8, 108.

[9] a) G. Decher, Science 1997, 277, 1232; b) K. Ariga, Y. Yamauchi, G. Rydzek, Q. M. Ji, Y. Yonamine, K. C. W. Wu, J. P. Hill, Chem. Lett. 2014, 43, 36.

[10] J. L. Zhao, M. Spasova, Z. A. Li, M. Zharnikov, Adv. Funct. Mater. 2011, 21, 4724.

[11] M. Pauly, B. P. Pichon, A. Demortiere, J. Delahaye, C. Leuvrey, G. Pourroy, S. Begin-Colin, Superlattice Microst. 2009, 46, 195.

[12] T. S. Yoon, J. Oh, S. H. Park, V. Kim, B. G. Jung, S. H. Min, J. Park, T. Hyeon, K. B. Kim, Adv. Funct. Mater. 2004, 14, 1062.

[13] a) D. Toulemon, B. P. Pichon, X. Cattoen, M. W. C. Man, S. BeginColin, Chem. Commun. 2011, 47, 11954; b) D. Toulemon, B. P. Pichon, C. Leuvrey, S. Zafeiratos, V. Papaefthimiou, X. Cattoen, S. Begin-Colin, Chem. Mater. 2013, 25, 2849; c) A. P. Upadhyay, D. K. Behara, G. P. Sharma, A. Bajpai, N. Sharac, R. Ragan, R. G. S. Pala, S. Sivakumar, ACS Appl. Mater. Inter. 2013, 5, 9554; d) S. Kinge, T. Gang, W. J. M. Naber, W. G. van der Wiel, D. N. Reinhoudt, Langmuir 2011, 27, 570.

[14] a) A. Bachtold, M. S. Fuhrer, S. Plyasunov, M. Forero, E. H. Anderson, A. Zettl, P. L. McEuen, Phys. Rev. Lett. 2000, 84, 6082; b) H. J. Dai, E. W. Wong, C. M. Lieber, Science 1996, 272, 523.

[15] a) Y. Selzer, L. T. Cai, M. A. Cabassi, Y. X. Yao, J. M. Tour, T. S. Mayer, D. L. Allara, Nano Lett. 2005, 5, 61; b) A. Salomon, D. Cahen, S. Lindsay, J. Tomfohr, V. B. Engelkes, C. D. Frisbie, Adv. Mater. 2003, 15, 1881.
[16] A. Kuzyk, Electrophoresis 2011, 32, 2307.

[17] a) X. Chen, Z. Guo, G. M. Yang, J. Li, M. Q. Li, J. H. Liu, X. J. Huang, Mater. Today 2010, 13, 28; b) T. Li, W. P. Hu, D. B. Zhu, Adv. Mater. 2010, 22, 286.

[18] G. Rydzek, L. Jierry, A. Parat, J.-S. Thomann, J.-C. Voegel, B. Senger, J. Hemmerle, A. Ponche, B. Frisch, P. Schaaf, F. Boulmedais, Angew. Chem. Int. Ed. 2011, 50, 4374.

[19] a) L. Hu, P. Zhao, H. Deng, L. Xiao, C. Qin, Y. Du, X. Shi, RSC Adv. 2014, 4, 13477; b) G. Rydzek, T. G. Terentyeva, A. Pakdel, D. Golberg, J. P. Hill, K. Ariga, ACS Nano 2014, 8, 5240; c) J. P. Collman, N. K. Devaraj, T. P. A. Eberspacher, C. E. D. Chidsey, Langmuir 2006, 22, 2457.

[20] a) W. Baaziz, B. P. Pichon, S. Fleutot, Y. Liu, C. Lefevre, J. M. Greneche, M. Toumi, T. Mhiri, S. Begin-Colin, J. Phys. Chem. C 2014, 118, 3795; b) G. Lamanna, A. Garofalo, G. Popa, C. Wilhelm, S. Begin-Colin, D. Felder-Flesch, A. Bianco, F. Gazeau, C. Menard-Moyon, Nanoscale 2013, 5, 4412; c) A. Garofalo, A. Parat, C. Bordeianu, C. Ghobril, M. Kueny-Stotz, A. Walter, J. Jouhannaud, S. Begin-Colin, D. Felder-Flesch, New J. Chem. 2014, 38, 5226.

[21] a) J. Park, K. J. An, Y. S. Hwang, J. G. Park, H. J. Noh, J. Y. Kim, J. H. Park, N. M. Hwang, T. Hyeon, Nat. Mater. 2004, 3, 891; b) J. Park, E. Lee, N.-M. Hwang, M. Kang, S. C. Kim, Y. Hwang, J.-G. Park, H.-J. Noh, J.-Y. Kim, J.-H. Park, T. Hyeon, Angew. Chem. 2005, 117, 2932.

[22] M. V. Voinova, M. Rodahl, M. Jonson, B. Kasemo, Phys. Scr. 1999, 59, 391.

[23] G. Sauerbrey, Z. Phys. 1959, 155, 206.

[24] G. Rydzek, P. Polavarapu, C. Rios, J.-N. Tisserant, J.-C. Voegel, B. Senger, P. Lavalle, B. Frisch, P. Schaaf, F. Boulmedais, L. Jierry, Soft Matter 2012, 8, 10336.

[25] a) T. S. Hansen, J. U. Lind, A. E. Daugaard, S. Hvilsted, T. L. Andresen, N. B. Larsen, Langmuir 2010, 26, 16171; b) S. O. Krabbenborg, C. Nicosia, P. K. Chen, J. Huskens, Nat. Commun. 2013, 4.

[26] J. F. Dayen, V. Faramarzi, M. Pauly, N. T. Kemp, M. Barbero, B. P. Pichon, H. Majjad, S. Begin-Colin, B. Doudin, Nanotechnology 2010, 21, 335303.

[27] a) K. H. Bhatt, S. Grego, O. D. Velev, Langmuir 2005, 21, 6603; b) D. J. Griffiths, Introduction to Electrodynamics, 3rd ed., Prentice Hall, Upper Saddle River, NJ 1998.

[28] J. F. Dayen, E. Devid, M. V. Kamalakar, D. Golubev, C. Guedon, V. Faramarzi, B. Doudin, S. J. van der Molen, Adv. Mater. 2013, 25, 400.

[29] N. W. Li, W. H. Binder, J. Mater. Chem. 2011, 21, 16717.

[30] A. Demortiere, P. Panissod, B. P. Pichon, G. Pourroy, D. Guillon, B. Donnio, S. Begin-Colin, Nanoscale 2011, 3, 225.

[31] K. A. Marx, Biomacromolecules 2003, 4, 1099.

Received: March 5, 2015

Revised: May 22, 2015

Published online: June 19, 2015 